\title{
Acoustic Identification of Wild Gray Wolves, Canis lupus, Using Low Quality Recordings
}

\author{
Cara B Hull, Caitlin M McCombe, \& Angela M Dassow* \\ Department of Biology, Carthage College, Kenosha, WI \\ bttps:/ / doi.org/10.33697/ ajur.2020.005 \\ Students: chull1@carthage.edu and cmccombe@carthage.edu \\ Mentor:adassow@carthage.edu*
}

\begin{abstract}
Invasive trapping and radio-collaring techniques are currently used by conservation biologists to study the population dynamics of gray wolves (Canis lupus). Previous research has found wolf howls can be used to determine individual identity on high quality recordings from captive animals, offering an opportunity for non-invasive monitoring of packs. We recorded wild wolves in Central Wisconsin to determine the effectiveness of these features in determining individuality in low quality recordings. The wolf howls analyzed were from two adult individuals from separate packs. Using a principle component analysis, maximum frequency and end frequency of the calls were determined to be most individualistic. Using these features in a discriminant function analysis, howls were able to be identified from individuals with 100\% accuracy. Gray wolves play an important role in ecosystem maintenance, however, the current monitoring techniques are costly and invasive. The creation of an easily accessible, noninvasive technique that can be used by individuals with a variety of technical backgrounds is necessary to address concerns faced by conservation efforts. To address these issues, all analyses performed used free or low-cost software, making this method of individual identification a useful alternative for conservation biologists.
\end{abstract}

\section{KEYWORDS}

Canis lupus lycaon; Gray Wolf; Acoustic Signatures; Howls; Tracking Method; Conservation; Vocal Individuality

\section{INTRODUCTION}

Populations of gray wolves, Canis lupus, are monitored by conservation biologists due to this species' importance in maintaining healthy ecosystems. ${ }^{1}$ However, tracking methods used to accomplish this are often highly invasive and costly. ${ }^{2}$ Radio-collaring techniques used to track these populations are limited due to a small range of detection, time requirement, and high cost. ${ }^{3}$ The trapping techniques required for radio-collars can have a negative effect on wolves, such as avoidance of the capture area, increased susceptibility to disease, increased susceptibility to predation, as well as a loss of reproductive success. ${ }^{2}$ Less invasive techniques have been suggested to track animals by analyzing their vocal individuality. 4,5 Wolf packs occupy large home ranges predominated by coniferous-hardwood forests. ${ }^{6}$ Gray wolf individuals can be identified based on acoustic features of their howls, a type of vocalization characterized by their low frequency and high amplitude that allows them to propagate over long distances in highly forested areas . ${ }^{7,8}$ In some mammals, size and social status has been shown to affect the individual's vocalizations. ${ }^{2}$ Wolf populations rely on howling as a form of communication within and across packs to signal territorial boundaries and social status. ${ }^{8}$ These attributes allow howls to be detected up to $10 \mathrm{~km}$ depending on terrain and weather conditions. ${ }^{10}$

The characteristics of wolf howls such as their maximum frequency, amplitude, duration, and harmonics are used to identify individuals. ${ }^{7,8}$ A prior study on captive Eastern gray wolves (Canis lupus lycaon) found that changes in the amplitude of the first four harmonics and the fundamental frequency of howls resulted in $95.5 \%$ accurate identification. ${ }^{7}$ The authors extracted amplitude harmonics on top of frequency and duration measurements from high-quality recordings of 89 howls of 6 captive adults to improve the identification accuracy of individual wolf vocalizations. A custom-made code in Matlab (Mathworks Inc. 2005) analyzed these features and classified individuals with high-levels of accuracy using a discriminant function analysis (DFA) compared to the free-source speech program Praat (95.5\% vs 82.8\%). Despite their success, these programs may not be feasible to learn by wildlife biologists needing to assess yearly pack compositions as they require extensive programming experience. Additionally, for the program that yielded the highest accuracy was very expensive which may limit widespread use. Also, some of the features that were measured can become attenuated in the low quality recordings these biologists would record in the wolves' natural environment outside captivity. ${ }^{6}$

This study aims to record wild gray wolves to determine whether individuality can be classified when howls become attenuated. Previous work identifying wild wolves achieved a 95.8\% accuracy using fundamental frequency with Raven Pro 1.3 (Cornell 
Laboratory of Ornithology), another expensive program. ${ }^{11}$ The authors identified individualistic features that differed from those used to classify captive animals. Our study tests whether the acoustic features used to identify individual gray wolves in lowquality recordings will differ from features used in high-quality recordings. We propose a cost-effective method for acoustic monitoring of gray wolves using low-quality recordings that is able to be used by researchers with a variety of analytical backgrounds.

\section{METHODS AND PROCEDURES}

Study site and subjects

We studied four wolf packs located in Central Wisconsin that included: East Mather, West Mather, Meadow Valley, and South Bluff. These packs have home ranges in close proximity to one another that varied in size from 20 to 120 square miles. Packs occupied sandy, upland conifer-hardwood forests of oak, aspen, and jack pine. ${ }^{6}$ Beyond this base habitat structure, each pack's territory held unique habitat types. Oak savannas predominated East Mather, urban development fragmented West Mather forests, and large marshes and flowages characterized South Bluff and Meadow Valley. The Wisconsin DNR recently surveyed these packs and provided the authors with the locations of their home ranges based on radio-collar, winter snow-tracking data, and howl surveys.

\section{Fieldwork}

Daily surveys began by searching for scat and tracks down drivable roads within a pack's territory to use as an indicator for wolf presence. Tracks indicated the direction the wolf travelled and its size. Scat and tracks indicated wolf activity which determined the route of nighttime howl surveys used to obtain vocalizations from individuals in the wild. Fieldwork was conducted throughout August 2017, late in the pup rearing season when wolves were more vocally active, but still unable to travel far distances quickly. ${ }^{8}$ We estimated wolf pack composition of adults, yearlings, and new pups of the year by the frequency of their howls since larger animals with longer vocal tracts emit lower frequency sounds. ${ }^{12}$

We conducted howl surveys from 9:00 p.m.-12:00 a.m. when wolves are most responsive. Around 9:00 p.m., the assembled recording equipment consisting of a DR-44WL recording device (TASCAM, Santa Fe Springs, CA, USA) with built-in XY microphones and an AT8035 shotgun condenser microphone (Audio-Technica U.S., Inc, Stow, OH, USA). During the howl survey, one researcher would howl following the protocols established in Harrington and Mech in order to encourage howl responses from wolf packs by imitating a lone wolf. ${ }^{13,14}$ Wolves responsive to simulated howls primarily stand their ground, while unresponsive wolves (predominantly lone wolves or small packs) are more likely to retreat.9,14 Wild wolves may also approach human howlers to identify its source or when several kilometers away better assess features that are attenuated by distance., 814 This suggested wolves considered imitated howls to be howls from conspecifics, as live howls elicit greater response than playback calls. ${ }^{8,9}$

A second researcher would record the entirety of the session in mono channel at a 32 bit depth and $44.1 \mathrm{kHz}$ sampling rate. If there was a positive response at any location we established the route to obtain closer proximity to the wolves, in order to acquire better recordings. At each of the howling spots we recorded the following data: meteorological data, GPS location, the number of wolf responses, approximate ages of wolves, and response distance and direction. The howl survey ended when vocal responses decreased around 12:00 a.m. Each night we rotated among the four packs, and also alternated researchers who howled to decrease the probability of wolves habituating to our voices. Wolves responded equally to all researchers.

\section{Labwork}

We filtered ambient noise from our recordings with Audition v. 2017.0.2 (Adobe, San Jose, CA, USA) by using Chebychev filters, noise reduction, and sound remover processes along with amplifier effects that increased the amplitude of the howl. Chebychev filters create a more immediate filtering effect on filtered out sounds. We used a high-pass filter on the Chebychev to remove sounds lower than a specific cut-off (around $300 \mathrm{~Hz}$ ) of ambient noise. Measurements from Audition spectrograms included: the fundamental frequency $\left(\mathrm{F}_{0}\right)$, maximum frequency $\left(\mathrm{F}_{\max }\right)$, dominant frequency $\left(\mathrm{F}_{\mathrm{dom}}\right)$, start frequency $\left(\mathrm{F}_{\text {start }}\right)$, middle frequency ( $F_{\text {middle }}$ ), end frequency $\left(\mathrm{F}_{\text {end }}\right)$, call duration, intercall interval $(\mathrm{ICI})$, dynamic range, minimum frequency $\left(\mathrm{F}_{\mathrm{min}}\right)$, bandwidth, and rises and falls from the (Table 1). In the current study, we selected these acoustic features based on past studies of canids and other organisms. ${ }^{8,15,16}$ We performed a Fast Fourier Transform (FFT) of 1024 and a window size of 0.5 seconds for call analysis. All features used to analyze distinctions between individuals were determined based off previous studies conducted on monk seals, gray wolves, and frogs in the genus Thoropa. ${ }^{7,15,16}$ Two researchers took measurements independently and compared results to minimize observer bias. We statistically analyzed the data using the program PAST3 v. 3.15. ${ }^{17}$ Welch's F test determined whether the amount of variation among an individual's howls were less than the amount of variation between individuals. Using PAST, a principal component analysis (PCA) clustered individuals howls based off feature similarity while also determining which features are most individualistic. With these results a discriminant function analysis (DFA) set the level of correct identification using the two most individualistic features. To better visualize the results from the DFA, we created a scatter plot using Matlab v. 
9.6.0. (Mathworks Inc., 2019). ${ }^{18}$ We removed three howls from the analysis: one from the Meadow Valley individual and two from the South Bluff individual. The end of the howl from the Meadow Valley adult cracked on the microphone, causing it to be removed from skewed frequency measurements. The low amplitude of two howls from the South Bluff individual resulted in inaccurate measurements over $100 \mathrm{~Hz}$ below the actual frequency, prompting their removal.

\section{RESULTS}

From the howl responses recorded during the month of August, the pack size and ages of individuals within the pack was approximated. All packs comprised of adults, yearlings, and juveniles used to identify howl responses (Table 2). We recorded a total of 20 minutes of usable howls containing howls overall from the four packs over several nights. Because a large portion of the recordings were chorus howls that overlapped in both time and frequency, the howls were unable to be used in the clustering analysis to identify individuals. Measurements included eight howls from a Meadow Valley adult wolf (Fig. 1) and thirteen howls from a South Bluff adult wolf (Fig. 2). Howls belonged to recordings of a single night for each individual. The measurements for minimum frequency, bandwidth, and rises and falls were removed from the analysis due to an inability to obtain accurate measurements from the spectrogram.

A)

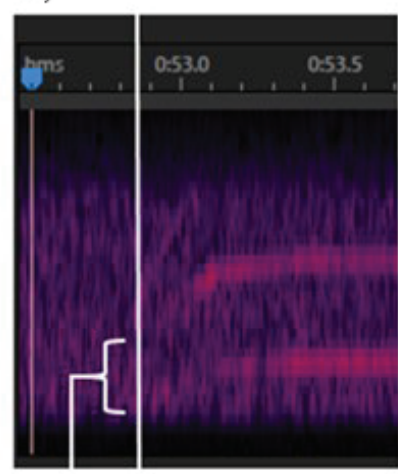

Time (hours:minutes:seconds)
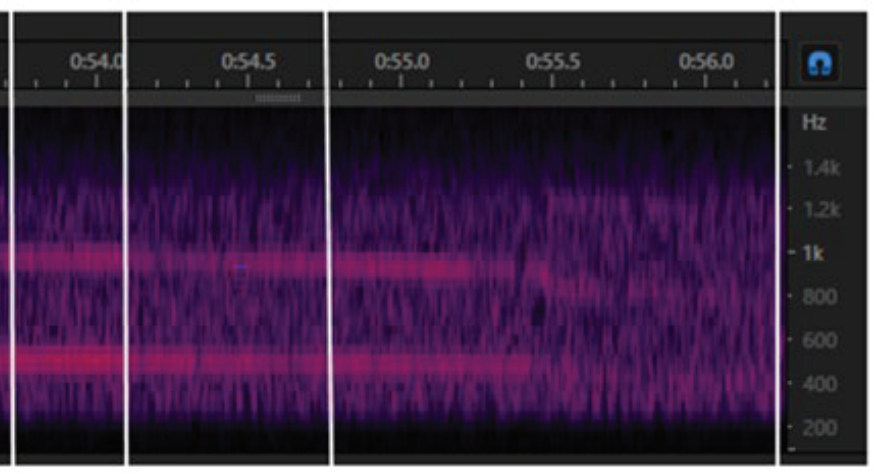

6
43

5

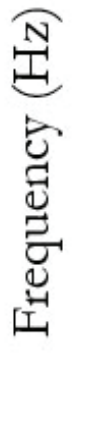

B)

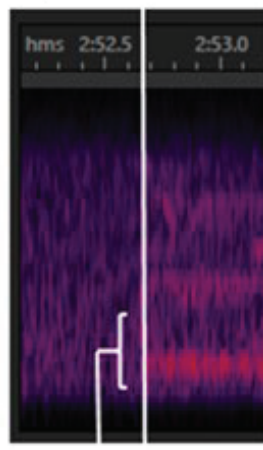

12
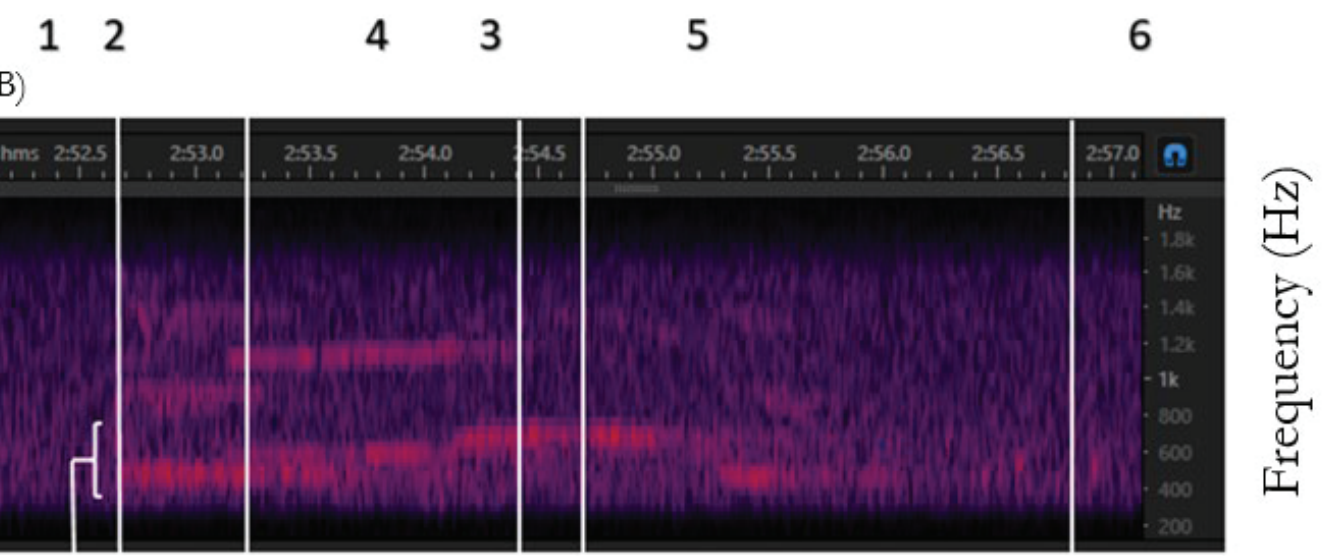

Figure 1. Sample of a howls from individual adult members of the A) Meadow Valley and B) South Bluff wolf packs in Central Wisconsin. The frequency is measured along the $\mathrm{y}$-axis in $\mathrm{Hz}$, time along the $\mathrm{x}$-axis in the hours:minutes:seconds into the recording file. Amplitude is depicted by variation in the intensity of color, with warmer color indicating higher amplitude. Each of the measured frequency units are indicated above as follows: $\mathrm{F}_{0}(1), \mathrm{F}_{\mathrm{Start}}(2), \mathrm{F}_{\mathrm{dom}}(3), \mathrm{F}_{\text {max }}(4), \mathrm{F}_{\text {mid }}$ (5), and $\mathrm{F}_{\text {end }}(6)$

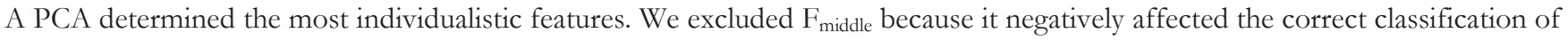
individuals. The results of this analysis clustered the howl into two separate ellipses that somewhat overlapped. This analysis found that the most individualistic feature was $\mathrm{F}_{\max }(56.16 \%$ variance $)$, followed by $\mathrm{F}_{\text {end }}(18.11 \%$ variance $)$, and $\mathrm{F}_{\text {start }}(14.43 \%$ variance). $F_{\max }$ corresponded to the highest eigenvalue, thus representing the principal component with the greatest weighting; $\mathrm{F}_{\text {start }}$ and $\mathrm{F}_{\text {dom }}$ have principal components with the second and third highest weighting (Table 3).

When comparing the features using the discriminant function analysis, $F_{\max }$ and $F_{\text {end }}$ gave the highest percentage of accurate identification, $100 \%$, and eigenvalue, 4.7502, between the howls of the two adult wolves (Figure 4). We removed two howls from 
the South Bluff individual and one howl from the Meadow Valley individual from the analysis because of a microphone crack and low amplitude. Of the remaining howls, 11/11 were correctly classified as the South Bluff individual and 7/7 were correctly classified as the Meadow Valley individual. Welch's F test was used to compare the means of $F_{\text {end }}$ and $F_{\max }$ between wolves to determine if they were significantly different. The p-value for $\mathrm{F}_{\text {end }}$ was found to be 0.0072 and the p-value for $\mathrm{F}_{\max }$ was 0.045 .

\begin{tabular}{|c|c|c|}
\hline Feature Analyzed & Description of Feature & Range of Measurements \\
\hline $\mathrm{F}_{0}$ & The fundamental frequency of the entire call & $430-570 \mathrm{~Hz}$ \\
\hline$F_{\max }$ & The maximum frequency of the entire call & $455-665 \mathrm{~Hz}$ \\
\hline $\mathrm{F}_{\mathrm{dom}}$ & The dominant frequency of the entire call & $450-550 \mathrm{~Hz}$ \\
\hline $\mathrm{F}_{\text {start }}$ & $\begin{array}{l}\text { The frequency at the start of the call where there is an initial major } \\
\text { rise in frequency }\end{array}$ & $330-540 \mathrm{~Hz}$ \\
\hline$F_{\text {middle }}$ & $\begin{array}{l}\text { The frequency at the middle of the call measured based on the start } \\
\text { and stop time of the call, this was determined by finding the accurate } \\
\text { measurement closest to the middle }\end{array}$ & $410-630 \mathrm{~Hz}$ \\
\hline $\mathrm{F}_{\text {end }}$ & $\begin{array}{l}\text { The frequency at the end of the call before there was a consistent } \\
\text { sudden drop in frequency }\end{array}$ & $345-500 \mathrm{~Hz}$ \\
\hline Call Duration & $\begin{array}{l}\text { The time from the first spike in frequency to the last drop in } \\
\text { frequency where the frequency is consistent }\end{array}$ & $2.5-4.5 \mathrm{~s}$ \\
\hline $\begin{array}{l}\text { Intercall Interval } \\
(\mathrm{ICI})\end{array}$ & $\begin{array}{l}\text { The time between the end of one howl and the beginning of another } \\
\text { determined by start and stop times }\end{array}$ & $1.5-17.0 \mathrm{~s}$ \\
\hline Dynamic Range & $\begin{array}{l}\text { The level of variation in amplitude between the start and stop time } \\
\text { of each call }\end{array}$ & $6.80-14.10 \mathrm{~dB}$ \\
\hline$F_{\min }$ & $\begin{array}{l}\text { The minimum frequency measured within the continuous call } \\
\text { including the start and end frequency }\end{array}$ & $\begin{array}{l}\text { No accurate measurements } \\
\text { could be obtained }\end{array}$ \\
\hline Bandwidth & $\begin{array}{l}\text { The maximum change in frequency throughout the call determined } \\
\text { by subtraction of } F_{\min } \text { from } F_{\max }\end{array}$ & $\begin{array}{l}\text { No accurate measurements } \\
\text { could be obtained }\end{array}$ \\
\hline Rises and Falls & $\begin{array}{l}\text { Rises and falls were counted based on the number of changes in the } \\
\text { fundamental frequency of at least } 25 \mathrm{Hertz}^{19}\end{array}$ & $\begin{array}{l}\text { No accurate measurements } \\
\text { could be obtained }\end{array}$ \\
\hline
\end{tabular}

Table 1. List of features that were measured in Adobe Audition v 2017.0.2. All of the features listed were determined based on past literature about determining vocal individuality, however, some were removed from the analysis due to ineffective measurements that are explained in the discussion below. These features were measured in Adobe Audition with the frequency analysis and amplitude statistics tools. 


\begin{tabular}{|l|l|l|l|l|}
\hline Wolf Pack & Adults & Yearlings & Pups & Number of howl responses \\
\hline Meadow Valley & $1-2$ & $1-2$ & $3-4$ & 9 \\
\hline South Bluff & $1-2$ & 0 & 1 & 4 \\
\hline East Mather & 2 & 1 & $3-4$ & 7 \\
\hline West Mather & 2 & 1 & 2 & 4 \\
\hline
\end{tabular}

Table 2. Estimated number of adults, yearlings, and pups, and the number of howl responses from four packs in Central Wisconsin. Of all the responses, we analyzed only two recordings, one from a Meadow Valley adult and one from a South Bluff adult.

A.

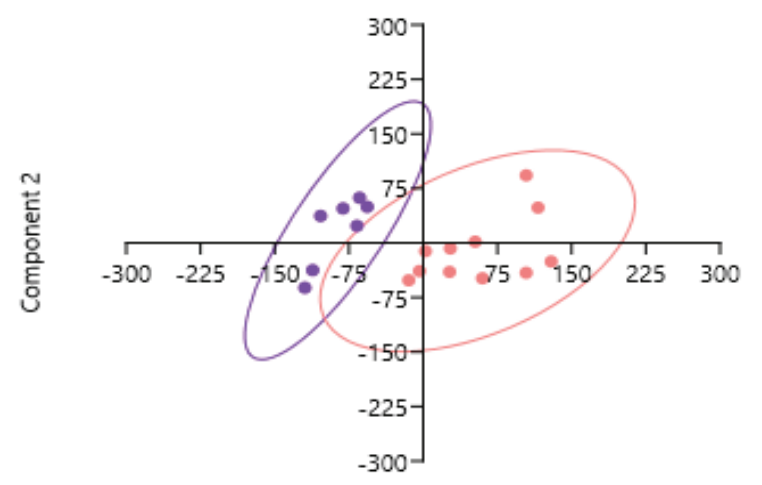

Component 1

B.

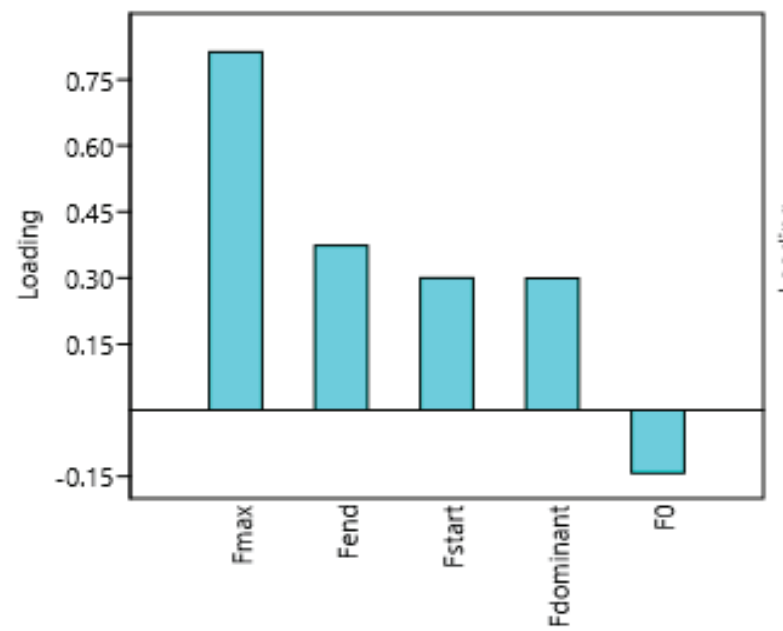

C.

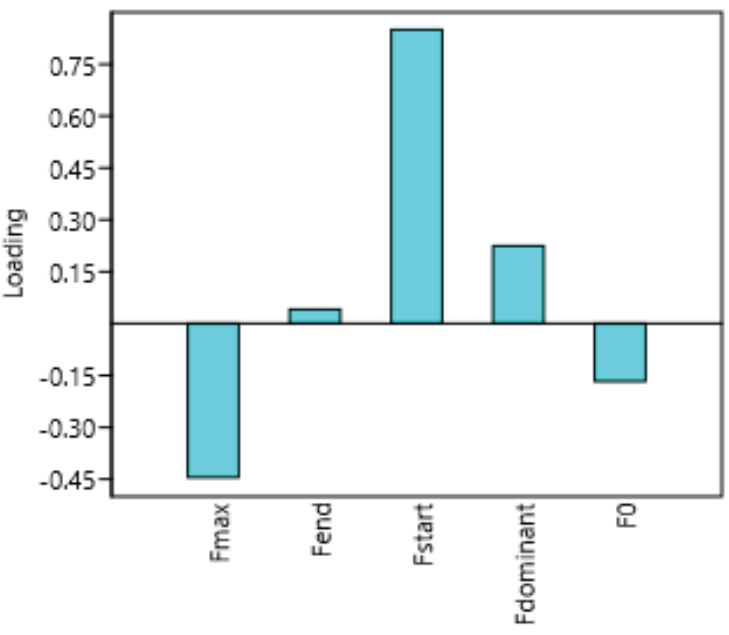

Figure 3. Principal component analysis (PCA) conducted using analyzable frequency measurements: $F_{\text {max }}, F_{\text {end }}, F_{\text {start, }}$ and $F_{0}$. A) Scatter plot for the South Bluff adult wolf howls (pink) and the Meadow Valley adult wolf howls (purple) with 95\% confidence interval ellipses surrounding the howls for each individual. The loading plots use eigenvalues to show the weighting of each acoustic feature in B) PC1 and C) PC2. 


\begin{tabular}{|c|c|}
\hline PC & Eigenvalue \\
\hline 1 & 6812.34 \\
\hline 2 & 2196.56 \\
\hline 3 & 1749.73 \\
\hline
\end{tabular}

Table 3. Chart of eigenvalue from principal component analysis. Results of principal component analysis with the principal component number (PC) and associated eigenvalue of the frequency measurements used for the PCA.

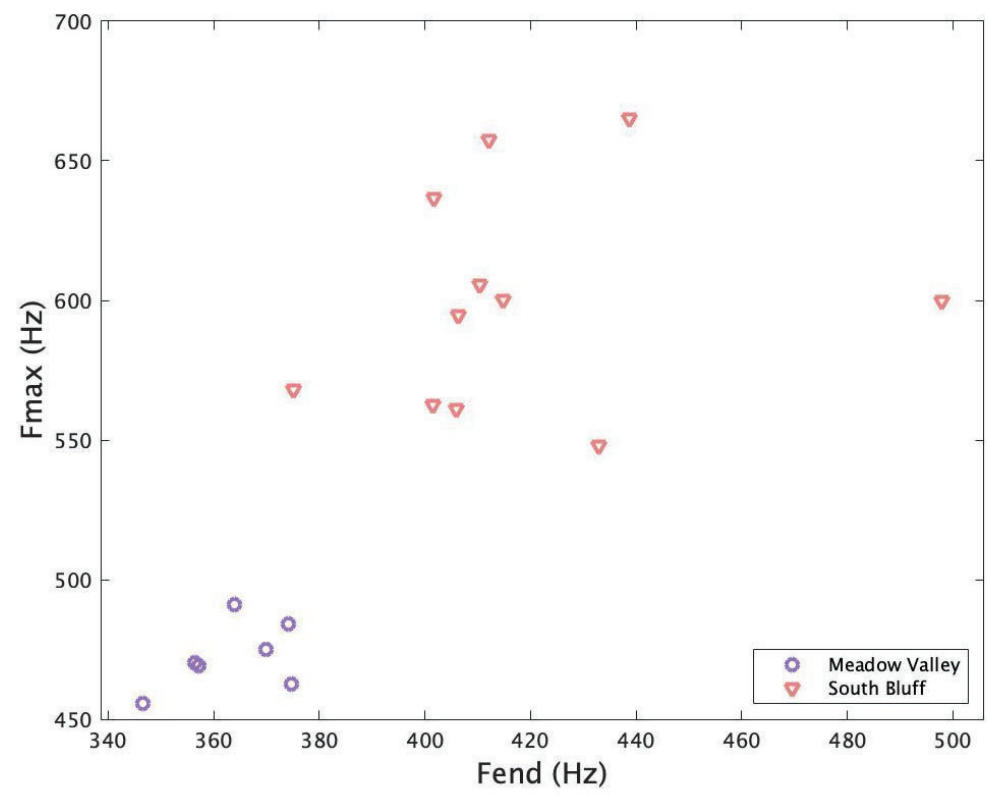

Fig 4. Scatterplot of the discriminant function analysis (DFA) using $F_{\max }$ and $\mathrm{F}_{\text {end. }}$ Given the sets of howls from two individuals, DFA trains a classifier to the data to maximize the difference between sets. Each point represents a howl at a particular Fend (x-axis) and Fmax (y-axis). Pink depicts howls from the South Bluff individual and purple depicts howls from the Meadow Valley individual. The DFA analysis correctly identified all 18 calls compared across the two adult individuals with $100 \%$ accuracy at an eigenvalue of 4.7502 . The DFA correctly assigned $11 / 11$ howls from the South Bluff individual and $7 / 7$ howls from the Meadow Valley individual.

\section{DISCUSSION}

This study determined whether the best identifying acoustic features in low-quality recordings differed from those used for highquality recordings. Using a PCA we determined that $F_{\max }, F_{\text {end }}$, and $F_{\text {start }}$ had the greatest amount of variance. We were able to

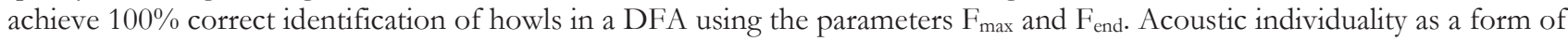
identification for conservation efforts has been used previously in other organisms (i.e. Common bottlenose dolphin (Tursiops truncatus), European bittern (Botaurus stellaris), and Italian wolf (Canis lupus italicus)). ${ }^{2,}{ }^{10}$ However, a cost effective, user-friendly method to identify gray wolves for conservation efforts has yet to be determined. Other studies on gray wolf individuality used amplitude and fundamental frequency to best discriminate howls from high-quality recordings. We tested a method to analyze howls of gray wolves from low-quality recordings and produced results that could accurately identify individuals using different acoustic features.

We filtered and measured howls using Audition and later differentiated individuals with 100\% accuracy from low-quality recordings. In contrast to the expensive price of a MATLAB license, we were able to achieve these results at the low monthly cost of an Audition license. Audition together with the free PAST3 statistical software showcases how wildlife managers can effectively assess pack composition without the need for invasive radio collaring equipment and expensive software. These programs also do not require prior coding knowledge and therefore are more user-friendly and broadly accessible. 
Throughout the field season, we recorded howls from many different individuals. Overlapping frequencies between the howls of individuals in choruses prevented us from using these howls in our analysis. Alpha adults play an important role in the social responsiveness of the pack. Wolves other than the alpha pair did not respond to simulated howls alone. ${ }^{8}$ These results are therefore limited to the alpha adults. If future studies determine methods to isolate howls from a chorus, our research can be expanded to all pack members. Passive acoustic monitoring of alphas can provide wildlife managers with the turnover rate of pack leaders. As more data accumulates, present recordings can be compared to howls recorded in future years in order to see if the same alpha pair still leads a particular pack.

We recorded the howls from each individual on a single night (Meadow Valley on 08/25/17 and South Bluff on 08/10/17). Other conspecifics howling did not interfere with the recording, so we know that these howls are attributed to the adult. Because we did not radiocollar individuals, we ran the DFA on howls obtained from a single night to identify that these howls belonged to a particular individual. However, we still can use DFA over multiple nights. The DFA differentiated the howls with 100\% accuracy, which indicates the reliability of utilizing these methods for individualistic classification.

Overlapping ellipses in PCA help determine the confidence of howls being categorized to a particular group. Although the PCA listed the middle frequency as highly individualistic, it resulted in increased overlap between the $95 \%$ ellipse of the individuals and was therefore excluded. This could have been due to variability in frequency change patterns across howls along with the duration of these frequency changes. In some howls sudden drops or rises in frequencies occurred at different portions within the call. The PCA found Fmax, PC1, and $\mathrm{F}_{\text {end, }}$ PC2 to have the highest eigenvalues and percent variance. None of the analyzed howls clustered in the overlap region between the $95 \%$ ellipses from these measurements. This signifies that $95 \%$ of the time the howls will likely cluster within these ellipses. Though the howls could possibly land within the overlap region, the howls did not fall within that area. When conducting the PCA three howls were removed, one from the Meadow Valley individual and two from the South Bluff individual. We removed the howl from the Meadow Valley adult because the microphone cracked at the end of the howl, causing skewed frequency measurements. We also removed the two howls from the South Bluff individual due to their low amplitude resulting in inaccurate measurements over $100 \mathrm{~Hz}$ below the actual frequency.

We were able to differentiate howls between the two individuals with $100 \%$ accuracy using $\mathrm{F}_{\max }$ and $\mathrm{F}_{\text {end. }}$. The $\mathrm{F}_{\text {end }}$ was not expected to be highly useful when identifying individuals in low quality recordings due to the degradation of the acoustics at the end of the call, especially over long distances. However, our analysis found $\mathrm{F}_{\text {end }}$ to be one of the most useful features for identifying wolf howls. When further comparing the recording conditions with the two wolves' of adult age, they were similar, suggesting $\mathrm{F}_{\text {end }}$ is a highly individualistic feature. The recording of the wolf from South Bluff was taken on a night when the weather was partially cloudy with light rain earlier that day. This was similar to the partially cloudy weather conditions of the recording night for the Meadow Valley individual. These individuals were both reported to be producing solo howls apart from the rest of their pack members. The distances were similar with the South Bluff individual being $0.64 \mathrm{~km}$ and the Meadow Valley individual being less than $0.32 \mathrm{~km}$ away. Since there was a high level of similarity between recording conditions, wolf traits, and distances of the recordings, the level of sound propagation for each of the howls would not have affected the measurement. Both the Meadow Valley and South Bluff individual howled on partly cloudy nights. No precipitation occurred during the howling sessions, but it lightly rained from 7:00-7:30 pm on the day we recorded the South Bluff adult. The daily high and low temperatures and wind speed/direction were comparable between the howling days: $71^{\circ} \mathrm{F}$ high and $54^{\circ} \mathrm{F}$ low with $5 \mathrm{mph} \mathrm{NW}$ winds for the Meadow Valley individual and $79^{\circ} \mathrm{F}$ high and $56^{\circ} \mathrm{F}$ low with $7 \mathrm{mph} \mathrm{W}$ for the South Bluff adult. For these reasons, $\mathrm{F}_{\text {end }}$ seems to be influenced by the characters of the wolf such as body size and social class rather than environmental factors. For example, larger animals have larger vocal tracts resulting in lower overall vocal frequencies. ${ }^{12}$ Adults therefore have lower $\mathrm{F}_{\text {end }}$ frequencies than pups.

During howl analysis, four features were immeasurable because of program limitations or low-quality recordings: $\mathrm{F}_{\min }$, bandwidth, intercall interval (ICI), and rises and falls. We originally included $\mathrm{F}_{\min }$ based on literature focused on determining individuality in Eastern gray wolves (Canis lupus bycaon). ${ }^{7,}{ }^{19}$ However, when using this feature in low quality recordings it was indistinguishable from the ambient noise. We were able to differentiate $\mathrm{F}_{\text {end }}$ from ambient noise, allowing us to use it as a measurable parameter due to a large frequency decrease following the end of the call. In the recordings, some portions of the howls were too low amplitude to be measured. This resulted in a high level of variability within the minimum frequencies across calls. This level of variability was attributed to the program detecting only ambient noise rather than the actual wolf howl. For this reason, the feature was determined to be unmeasurable. This inability to measure $\mathrm{F}_{\min }$ in the howls resulted in the loss of other features for analysis, including bandwidth since the minimum is necessary to calculate this measurement. A third feature that we determined to be unusable was duration between howls. Duration between howls was chosen because it was found to be useful in differentiating between six species of frogs within the genus Thoropa. ${ }^{15}$ Though the vocal production mechanisms vary greatly between frogs and wolves, this feature was explored because if successful, this could be used for solo and chorus howls. Due to the sample size of howls collected per individual and the feature only being able to be measured between two consecutive howls it resulted in a 
decreased number of measurements per individual wolf with some being disrupted by barks or unmeasurable howls. Aside from this, the howls showed no form of consistency in how often they were emitted, therefore, this feature was removed from the analysis.

Frequency modulation throughout the call of organisms was also found to be highly useful in past studies. In a study analyzing timber wolf howls, measurements were made on the number of abrupt changes in frequency that were different than the fundamental frequency by more than $25 \mathrm{~Hz} \cdot{ }^{17}$ More recently, in a study on dolphins' signature whistles, frequency modulation throughout the call was calculated by using algorithms to compare frequency changes at various points in time. ${ }^{20}$ The method needed for quantitative analysis of the frequency modulation across the entire call is highly complex. Literature that uses this form of analysis relies heavily on programs that are costly, making the method less accessible for conservation efforts that have limited budgets. This method also requires a strong background in computer programing, removing the practicality of its use for people with a large assortment of backgrounds and skill sets. When applying the simpler method of measuring the number of abrupt changes, it becomes difficult to define set parameters because of the high level of variability in temporal and frequency aspects within howls. This leads to a high level of observer bias being introduced into the measurements, therefore, rises and falls were removed from the analysis.

\section{CONCLUSIONS}

The use of bioacoustics in conservation efforts has become a topic of rising interest because of its ability to offer a noninvasive method to track vocalizing populations.,21 Thus far research on the topic of bioacoustics in conservation efforts has shown promising results, especially within gray wolf populations where research has been able to identify adult wolves using howls with $100 \%$ accuracy. ${ }^{7}$ However, current analyses of animal vocalizations use complex methods and expensive programs that are not user-friendly. With current methods, the use of vocal identity to track populations becomes challenging for widespread use by conservation biologists due to an inability to access many of the supplies and a lack of training in skills needed for these methods. Through this research we propose an accessible and inexpensive method to track wolf populations, including turnover rates and pack size. Low-cost programs were selected for all of the analyses that are targeted towards use by people with a variety of backgrounds in computational training. The most individualistic features have also been identified within the howls so analyses can be conducted in shorter amounts of time with only the features that were found to be reliably indicative of individuality. To further test the viability of these methods in the future we will increase the sample size of the analysis and conduct the study over multiple years on the same packs. This will allow us to determine the usefulness of these methods to track turnover rates.

\section{ACKNOWLEDGEMENTS}

The authors would like to express their appreciation to Dick Thiel, Norma Donovan, Ray Leonard, Linda Nelson, Bob Sherman, and the Timber Wolf Information Network for advising on wolf pack information, Sandhill Wildlife Area for the utilization of their facilities, Carthage College Natural and Social Science Division for sponsoring the Summer Undergraduate Research Experience (SURE) program, and the Carthage College Biology Department for supporting undergraduate research.

\section{REFERENCES}

1. Fortin, D., Hawthorne, B., Boyce, M., Smith, D., Duchesne, T. and Mao, J. (2005) Wolves influence elk movements: behavior shapes a trophic cascade in Yellowstone National Park. Ecology 86: 1320-1330. bttps:// doi.org/ 10.1890/04-0953

2. Terry, A., Peake, T. and McGregor, P. (2005) The role of vocal individuality in conservation. Frontiers in Zoology 2: 10. bttps:// doi.org/10.1186/1742-9994-2-10

3. Harris, S., Cresswell, W.J., Forde, P.G., Trewhella, W.J., Woollard, T. and Wray, S. (1990) Home-range analysis using radiotracking data-a review of problems and techniques particularly as applied to the study of mammals. Mammal Review 20: 97-123. bttps:// doi.org/10.1111/j.1365-2907.1990.tb00106.x

4. Hartwig, S. (2005) Individual acoustic identification as a non-invasive conservation tool: an approach to the conservation of the African Wild Dog, Lycaon pictus (Temminck, 1820). Bioacoustics 15: 35-50. bttps:/ / doi.org/10.1080/09524622.2005.9753537

5. Darden, S., Dabelsteen, T. and Pedersen, S. (2003) A potential tool for swift fox (Vulpes velox) conservation: individuality of long-range barking sequences. Journal of Mammalogy 84: 1417-1427. https:// doi.org/10.1644/BEM-031

6. Brown, R.T. and Curtis, J.T. (1952) The Upland Conifer-Hardwood Forests of Northern Wisconsin. Ecological Monographs. 22(3):217-234. doi:10.2307/1943566

7. Root-Gutteridge, H., Bencsik, M., Chebli, M., Gentle, L.K., Terrell-Nield, C., Bourit, A. and Yarnell, R.W. (2014) Improving individual identification in captive Eastern grey wolves (Canis lupus lycaon) using the time course of howl amplitudes. Bioacoustics-the International Journal of Animal Sound and Its Recording 23: 39-53. bttps:/ / doi.org/10.1080/09524622.2013.817318

8. Suter, S.M., Giordano, M., Nietlispach, S., Apollonio, M. and Passilongo, D. (2017) Non-invasive acoustic detection of wolves. Bioacoustics-the International Journal of Animal Sound and Its Recording 26: 237-248. https:// doi.org/10.1080/09524622.2016.1260052

9. Harrington, F. and Mech, D. (1979) Wolf howling and its role in territory maintenance. Behaviour, 68: 207-249. doi: $10.1163 / 156853979$ X00322 
10. Joslin P.W.B. (1967) Movements and home sites of timber wolves in Algonquin park. American Zoologist 7: $279-288$. bttps:// doi.org/10.1093/icb/7.2.279

11. Passilongo D., Buccianti A, Dessi-Fulgheri F., Gazzola A., Zaccaroni M. and Apollonio M. (2012) The acoustic structure of wolf howls in some eastern Tuscany (central Italy) free ranging packs. Bioacoustics. 19:159-175. bttps:/ / doi.org/ 10.1080/09524622.2010.9753622

12. Faragó, T., Townsend, S. and Range, F. (2014) The information content of wolf (and dog) social communication, in Biocommunication of Animals. (Witzany, G., Ed.) 1st ed., 41-62. Springer, Dordrecht.

13. Harrington, F. and Mech, D. (1982) An analysis of howling response parameters useful for wolf pack censusing. The Journal of Wildlife Management 46: 686-693. doi: 10.2307/3808560

14. Leblond, M., Dussault, C. and St-Laurent, M.H. (2017) Space use by gray wolves (Canis lupus) in response to simulated howling: a case study and a call for further investigation. Canadian Journal of Zoology. 95(3): 221-226. doi:10.1139/cjz-2016-0191

15. Charrier, I., Marchesseau, S., Dendrinos, P., Tounta, E. and Karamanlidis, A.A. (2017) Individual signatures in the vocal repertoire of the endangered Mediterranean monk seal: new perspectives for population monitoring. Endangered Species Research 32: 459-470. https://doi.org/10.3354/esn00829

16. Nunes-de-Almeida, C.H.L., Assis, C.L., Feio, R.N. and Toledo, L.F. (2016) Redescription of the advertisement call of five species of Thoropa (Anura, Cycloramphidae), including recordings of rare and endangered species. Plos One 11: e0162617. bttps:/ / doi.org/10.1371/journal.pone.0162617

17. Hammer, Q., Harper, D.A.T., Ryan, P.D. (2001) PAST: Paleontological Statistics software package for education and data analysis. Palaeontologia Electronica 4(1): 9.

18. MATLAB. (2019). MATLAB version 9.6.0. 1114505 (R2019a). The Mathworks Inc. Natick, Massachusetts.

19. Tooze, Z.J., Harrington, F.H. and Fentress, J.C. (1990) Individually distinct vocalizations in timber wolves, Canis lupus. Animal behavior 40: 723-730. https:/ / doi.org/10.1016/S0003-3472(05)80701-8

20. Kershenbaum, A., Sayigh, L.S. and Janik, V.M. (2013) The encoding of individual identity in dolphin signature whistles: how much information is needed?. Plos One 8: e77671. https://doi.org/10.1371/journal.pone.0077671

21. Palacios V, Font E and Márquez R. (2007) Iberian wolf howls: acoustic structure, individual variation, and a comparison with North American populations. Journal of Mammalogy 88(3): 606-613. https:/ / doi.org/10.1644/06-MAMM-A-151R1.1

\begin{abstract}
ABOUT STUDENT AUTHORS
Cara Hull is a student research assistant graduating from Carthage College in spring 2019 with a Bachelor of Arts in Biology with a minor in Chemistry. She currently studies bioacoustics with the intention to focus on research in conservation and genetics in the future. In fall 2019 she will be continuing her education at the University of Southern California pursuing a PhD in Molecular Biology.

Caitlin McCombe is a student research assistant who will be graduating in spring 2020 from Carthage College with a Bachelor of Arts in Biology and a minor in Chemistry. She currently studies bioacoustics and intends to pursue this research area into graduate school, but within the field of marine biology. In summer 2019, she will be working with the Read Lab at Duke University studying pilot whales.
\end{abstract}

\title{
PRESS SUMMARY
}

Current monitoring of gray wolves utilizes invasive trapping and radio-collaring methods to track population dynamics. Individual identity can be determined using wolf howls with high quality recordings of captive animals. Utilizing this knowledge, the following study aims to create a low cost method to track wild gray wolves in Central Wisconsin using acoustic features previously identified as individualistic in captive wolf analyses. Upon completion of future testing, the following method will provide a novel and non-invasive technique for monitoring gray wolves for use in wildlife management. 